\title{
Detection of anti-Leishmania infantum antibodies in sylvatic lagomorphs from an epidemic area of Madrid using the indirect immunofluorescence antibody test
}

\author{
Inmaculada Moreno ${ }^{a}$, Julio Álvarez ${ }^{b}$, Nerea García ${ }^{c}$, Santiago de la Fuente ${ }^{\mathrm{d}}$, \\ Irene Martínez ${ }^{\mathrm{c}}$, Eloy Marino ${ }^{\mathrm{d}}$, Alfredo Toraño ${ }^{\mathrm{a}, *}$, Joaquin Goyache ${ }^{\mathrm{e}}$, \\ Felipe Vilas ${ }^{\mathrm{d}}$, Lucas Domínguez ${ }^{\mathrm{c}, \mathrm{e}}$, Mercedes Domínguez ${ }^{\mathrm{a}}$ \\ a Área de Inmunología, Unidad de Inmunología Microbiana e Inmunogenética, Instituto de Salud Carlos III, Mahadahonda, \\ 28220 Madrid, Spain \\ b Instituto Ramón y Cajal de Investigación Sanitaria (IRYCIS), 28034 Madrid, Spain \\ c Centro de Vigilancia Sanitaria Veterinaria (VISAVET), Universidad Complutense Madrid, 28040 Madrid, Spain \\ d Dirección General de Ordenación e Inspección, Consejería de Sanidad de la Comunidad de Madrid, 28001 Madrid, Spain \\ e Departamento de Sanidad Animal, Facultad de Veterinaria, Universidad Complutense Madrid, 28040 Madrid, Spain
}

\section{A R T I C L E I N F O}

\section{Article history:}

Received 3 May 2013

Received in revised form 7 October 2013

Accepted 15 October 2013

\section{Keywords:}

Leishmaniosis

Immunofluorescence

Incidental reservoirs

Hare

Anti-Leishmania antibodies

Promastigote epitope expression

\begin{abstract}
A B S T R A C T
An outbreak of human leishmaniosis was confirmed in the southwest of the province of Madrid, Spain, between July 2009 and December 2012. Incidence of Leishmania infection in dogs was unchanged in this period, prompting a search for alternative sylvatic infection reservoirs. We evaluated exposure to Leishmania in serum samples from animals in the area with an indirect immunofluorescence test (IFAT). Using promastigotes from six culture passages and a $1 / 25$ threshold titer, we found anti-Leishmania infantum seroreactivity in $9.3 \%$ of cats ( 4 of 43 ), $45.7 \%$ of rabbits (16/35) and $74.1 \%$ of hares $(63 / 85)$. Use of promastigotes from $>10$ in vitro passages resulted in a notably IFAT lower titer, suggesting antigenic changes during extended culture. Postmortem inspection of seropositive animals showed no clinical signs of infection. The results clearly suggest that asymptomatic hares were the main reservoir in the outbreak, and corroborate IFAT as a sensitive serological surveillance method to detect such cryptic Leishmania infections.
\end{abstract}

(c) 2013 Elsevier B.V. All rights reserved.
The leishmanioses are a group of vector-borne diseases caused by parasites of the genus Leishmania (Bañuls et al., 2007). Infection is transmitted through the bite of infected phlebotomine sandflies which inoculate promastigotes in host skin while probing for a blood meal (Bates, 2007). Most leishmanioses are zoonotic, and in rural areas Leismania maintains persistent foci by preferentially infecting certain mammalian hosts as primary, or infection reservoirs (Ashford, 1996). Depending on environmental conditions, Leishmania can perpetuate their endemic cycle by

\footnotetext{
* Corresponding author. Tel.: +34 91822 3610; fax: +34 918223423 .

E-mail address: atorano@isciii.es (A. Toraño).
}

infecting other hosts, termed incidental or secondary reservoirs, which act as "liaisons" with the final host in the transmission chain (Ashford, 2003).

In Mediterranean countries, the Americas, the Middle East and China, Leishmania infantum is the etiological agent of visceral and cutaneous leishmaniosis (Boelaert et al., 2000). In most areas where $L$. infantum is endemic, dogs are the main peridomestic reservoir (Baneth et al., 2008), although mammals other than dogs can be naturally infected and can have a role as secondary reservoirs (Gramiccia, 2011); in the Iberian peninsula, these include the black rat (Morillas Márquez et al., 1985), horse (SolanoGallego et al., 2003), cat (Martín-Sánchez et al., 2007; Ayllón et al., 2008, 2012), red fox (Criado-Fornelio et al., 
2000), rabbit (Chitimia et al., 2011), hare (Molina et al., 2012), and several wild carnivores (Sobrino et al., 2008; Millán et al., 2011).

During the 2009-2012 leishmaniosis outbreak in the southwest of the province of Madrid, reported human cases rose from 12 to 25 cases/year to 415 cases in a 3.5 -year period (36.7\% visceral, $63.3 \%$ cutaneous), and the mean number of sand flies trapped from $30 \mathrm{~m}^{-2}$ in Madrid province to $45.3 \mathrm{~m}^{-2}$ in the perimeter of the outbreak, although the incidence of Leishmania infected dogs during the same period increased only slightly in dogs in canine shelters (3.6\%) (SNEDO, 2012; Arce et al., 2013). These data suggested that a mammal other than dog was acting as a parasite reservoir. To identify potential Leishmania reservoirs, we used IFAT to screen for anti-leishmania antibodies in sera of stray cats, as well as wild rabbits and hares in the area of the Madrid epidemic.

Blood samples were collected from 43 cats (Felis catus), 35 rabbits (Oryctolagus cuniculus) and 85 hares (Lepus granatensis) captured within the perimeter of the outbreak in a convenience sampling for an epidemiological survey. Animals were inspected postmortem for external and visceral signs of disease (spleno- and hepatomegalia). Spleen and liver samples were collected for molecular (PCR) and cytological tests. Serum aliquots from clotted blood were stored at $-20^{\circ} \mathrm{C}$.

For the IFAT, promastigotes of $L$. infantum (M/CAN/ES/97/10,445) zymodeme MON-1 were derived from spleens of infected hamsters. Macerated spleen was cultured $\left(26^{\circ} \mathrm{C}\right)$ in diphasic blood-agar Novy-McNealNicolle medium-coated tubes, and newly developed promastigotes cultured in complete RPMI 1640 medium as described (Moreno et al., 2007). Cultures were incubated $\left(26^{\circ} \mathrm{C}\right)$ until early stationary phase, promastigotes harvested by centrifugation $\left(1500 \times \mathrm{g}, 20^{\circ} \mathrm{C}, 15 \mathrm{~min}\right)$, washed twice in RPMI 1640 , and adjusted to $2 \times 10^{7}$ cells $/ \mathrm{ml}$. For culture passaging, $9 \mathrm{ml}$ complete medium were added to $1 \mathrm{ml}$ early stationary phase promastigote suspension and cultured until cell density again reached early stationary phase growth. This culture sequence was maintained for at least 40 passages.

We then coated 24-well glass slides with $10 \mu \mathrm{l} /$ well aliquots of promastigotes $\left(2 \times 10^{7} \mathrm{ml}^{-1}\right)$. Promastigotes were allowed to dry, fixed in acetone:methanol $(1: 1, \mathrm{v} / \mathrm{v}$; $\left.10 \mathrm{~min},-20^{\circ} \mathrm{C}\right)$, air-dried, and stored at $-20^{\circ} \mathrm{C}$. Serum samples $(10 \mu \mathrm{l})$ were analyzed by serial doubling dilution $(1 / 12.5-1 / 3200)$ in PBS, and incubated $\left(37^{\circ} \mathrm{C}, 30 \mathrm{~min}\right)$ in wells coated with $L$. infantum promastigotes grown for $3,5,10,20,30$ and 40 successive in vitro passages. Slides were washed three times ( 10 min each) in PBS, and $10 \mu l$ fluorescein-labeled goat anti-rabbit immunoglobulin (4050-02; Southern Biotech, AL, USA; crossreactive with hare immunoglobulin) or goat anti-cat immunoglobulin (102-095-003; Jackson ImmunoResearch, PA, USA) in PBS supplemented with Evans blue (diluted $1 / 10^{4}$ ) were added to wells and incubated $\left(37^{\circ} \mathrm{C}, 30 \mathrm{~min}\right)$. The slides were washed three times (10 min each) in PBS, rinsed in water, mounted in glycerol and examined in a fluorescence microscope (Zeiss Axioskop 40; 40× magnification).

To detect anti-Leishmania antibodies, a threshold value was established at $1 / 25$ dilution with sera from naïve

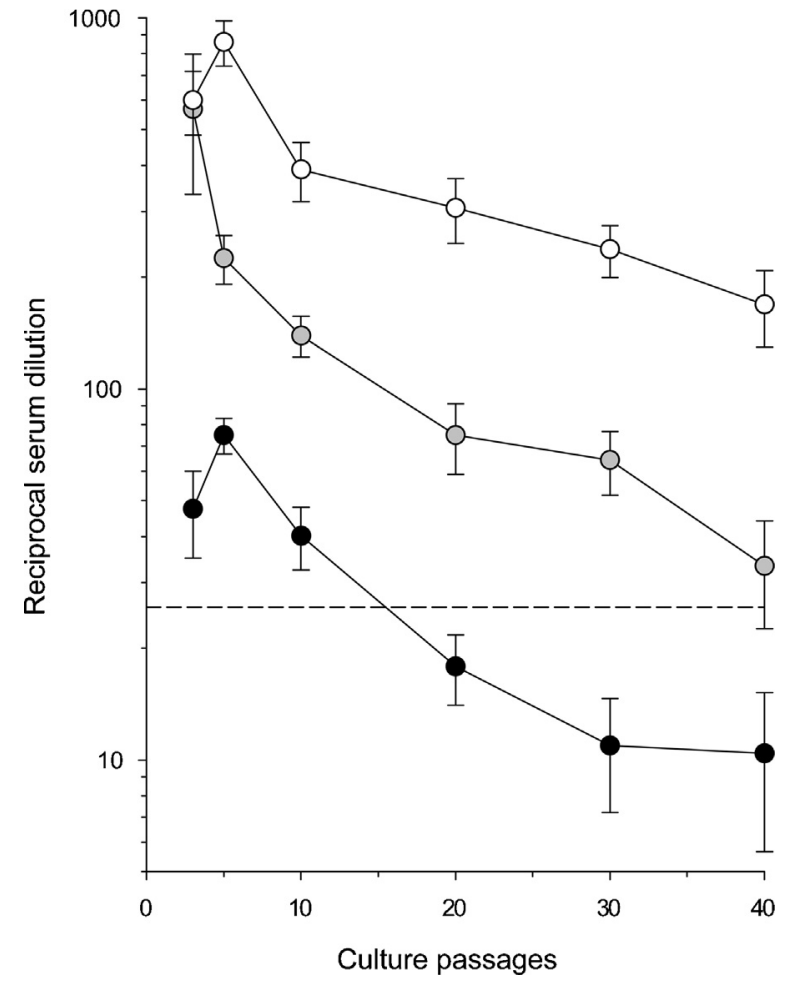

Fig. 1. Anti-L. infantum reactivity of hare sera preclassified as with high (white circle; $1 / 800-1 / 3200, n=4$ ), medium (gray circle; $1 / 200-1 / 400$; $n=7$ ) and low (black circle; $1 / 25-1 / 100 ; n=7$ ) titers when analyzed by IFAT with promastigotes from $3,5,10,20,30$ and 40 in vitro culture passages (each serum was tested in two independent analyses). Bars show mean \pm SEM of antibody titer values and the dashed line indicates the threshold titer $(1 / 25)$.

NZW rabbits and cat serum from a Leishmania-seronegative cat serum bank. Anti-Leishmania antibody titers for cat, rabbit and hare sera were measured in slides coated with promastigotes from six culture passages (Table 1); titers $\geq 1 / 50$ were considered positive. As shown, $9.3 \%$ of cats $(4 / 43), 45.7 \%$ of rabbits $(16 / 35)$ and $74.1 \%$ of hares (63/85) had anti-promastigote antibodies, indicating a significantly (Pearson Chi-square, $p<0.05$ ) larger percentage of reactive hares. In addition to the higher seropositivity rate in hare samples, the percentage of samples with high antibody titers $(>1 / 400)$ was also significantly (Pearson Chi-square, $p<0.05)$ higher for hares $(31.8 \% ; 27 / 85)$, than for rabbits $(17.1 \% ; 6 / 35)$ or cats $(2.3 \% ; 1 / 43)$. When we performed IFAT on slides coated with promastigotes from $>10$ passages, we found a substantial decrease in the serum titer, particularly in samples with low titer $(\leq 1 / 100)$ in the earlier assay, which could affect interpretation of the test. In two independent analyses, we analyzed sera from individual hares with strong positive (range $1 / 800-1 / 3200$, $n=4)$, medium ( $1 / 200-1 / 400, n=7)$ and weak $(1 / 50-1 / 100$, $n=7)$ anti-Leishmania antibody titer, on slides coated with promastigotes from $3,5,10,20,30$ and 40 culture passages (Fig. 1).We observed a differential effect of passage number on test results; whereas sera with high anti-promastigote titers remained positive even when analyzed with promastigotes from 40 culture passages, weak reactive sera 
Table 1

Anti- L. infantum antibody reactivity of cat, rabbit and hare sera in IFAT using promastigotes from six in vitro culture passages.

\begin{tabular}{|c|c|c|c|c|}
\hline \multirow[t]{2}{*}{ Antibody reactivity } & \multirow[t]{2}{*}{ Reciprocal serum dilution } & \multicolumn{3}{|c|}{ Number (\%) positive sera } \\
\hline & & Cat $(n=43)$ & Rabbit $(n=35)$ & Hare $(n=85)$ \\
\hline None & 12.5 & $35(80.8)$ & $14(39.9)$ & $18(21.1)$ \\
\hline Low & $\begin{array}{l}25^{a} \\
50\end{array}$ & $\begin{array}{l}4(9.0) \\
2(4.6)\end{array}$ & $\begin{array}{l}5(14.3) \\
3(8.6)\end{array}$ & $\begin{array}{c}4(4.7) \\
21(25.0)\end{array}$ \\
\hline Medium & $\begin{array}{l}100 \\
200 \\
400\end{array}$ & $\begin{array}{l}1(2.3) \\
0 \\
1(2.3)\end{array}$ & $\begin{array}{l}4(11.4) \\
3(8.6) \\
4(11.4)\end{array}$ & $\begin{array}{c}6(7.0) \\
9(10.6) \\
16(18.8)\end{array}$ \\
\hline High & $\begin{array}{r}800 \\
1600 \\
3200\end{array}$ & $\begin{array}{l}0 \\
0 \\
0\end{array}$ & $\begin{array}{l}1(2.8) \\
1(2.8) \\
0\end{array}$ & $\begin{array}{l}3(3.5) \\
4(4.7) \\
4(4.7)\end{array}$ \\
\hline
\end{tabular}

a Threshold titer.

(titer 1/50-1/100) tested negative with promastigotes from $>10$ passages.

IFAT is the recommended reference test for serological diagnosis of canine leishmaniosis by the World Organization for Animal Health (OIE) (OIE Terrestrial Manual, 2008). When performed with serial serum dilutions, IFAT is sensitive, highly specific, and provides end-point titer data. Our results with promastigotes grown for six culture passages showed that $9.3 \%$ of cats, $45.7 \%$ of rabbits and $74.1 \%$ of hares had positive antibody responses, with titers $\geq 1 / 50$. These results coincide with previous xenodiagnostic experiments showing that four of seven seropositive hares trapped in the outbreak region transmitted $L$. infantum to sand flies (Molina et al., 2012), and PCR analyses indicating that $8.6 \%$ of rabbits and $43.5 \%$ of hares were Leishmania DNA-positive (SNEDO, 2012). The importance of cat infection by Leishmania in this outbreak is unclear, as the percentage of cats with a titer $\geq 1 / 50$ is considerably lower than that of lagomorphs; cats are nonetheless known low antibody responders to Leishmania (Maia et al., 2010). Our data clearly suggest that hares were the main incidental reservoir in the Madrid L. infantum epidemic. The strong antibody response, the large number of Leishmania DNA PCR-positive individuals, and the lack of visual signs of disease at post-mortem inspection suggest that the hare's immune system is able to control active infection. The animals would thus remain asymptomatic while harboring the parasites, making them competent Leishmania reservoirs. Rabbits can become accidental Leishmania hosts and be infected, although it is stated that they do not transmit the parasite (Chelbi et al., 2008), and in Leishmania-endemic areas show low risk of developing chronic infection (Chitimia et al., 2011). Rabbits develop efficient natural (Ulrich et al., 1968) and adaptive (Schmunis and Herman, 1970) anti-trypanosomatid humoral responses, with a strong promastigote immune adherence reaction, and have a potent complement system (Moreno, 2010). The lower anti-Leishmania antibody titer and the smaller percentage of Leishmania PCR-positive rabbits compared to hares might be due to a better ability of rabbit innate and cell-mediated immunity to maintain low parasite burden and generate a state of premunition that impedes reservoir competence.

Land use conversion resulting habitat change to is likely to have reduced predators in the outbreak zone and boosted leporid populations, leading to a sand fly boom and increased sand fly-hare contact/biting/transmission. Recent data on vector attraction by hosts trapped in the outbreak area rank Phlebotomus perniciosus blood feeding preferences as hares $>$ humans $>$ cats (Jiménez et al., 2013). The differences we measured in hare, rabbit, and cat antibody responses to $L$. infantum might be a function of the number of sand fly bites ("antigenic boosts") received by each host species in its lifetime; this in turn would affect anti-Leishmania antibody responses as measured by IFAT.

Our IFAT data showed lower anti-Leishmania antibody titer in slides coated with parasites with $>10$ passages, and fell markedly with high passage-number promastigotes ( $\geq 20$ passages; Fig. 1 ). Weakly positive sera could thus give false negative results in IFAT performed with "aged" promastigotes. Official IFAT guidelines do not specify the characteristics of promastigotes to be used for the test (OIE Terrestrial Manual, 2008), and our data indicate that high passage number ("aged") parasites should be avoided. In Leishmania metacyclogenesis and after multiple in vitro culture passages, promastigotes undergo changes in morphology (Wheeler et al., 2011), virulence (Moreira et al., 2012), and immunodominant antigens modify their expression (Lei et al., 2010) or become masked (Karp et al., 1991). This could explain why anti-Leishmania antibodies from natural infections recognize epitopes on "young" promastigotes more efficiently than on long-term cultured parasites.

In conclusion, the results of our study point to sylvatic hares as the main incidental reservoir in the Madrid leishmaniosis outbreak, and confirm IFAT as a reliable serological method for leishmaniosis surveillance, provided that low passage number promastigotes are used as antigenic target.

\section{Conflict of interest}

None.

\section{Acknowledgments}

The authors thank Ana Belén Martín, and Soledad Crespo for excellent technical assistance, and Catherine Mark for critical reading and editorial assistance. J.A. received a Sara 
Borrell post-doctoral contract (CD11/00261, Ministerio de Ciencia e Innovación). This work is a contribution to the EU FP7 ANTIGONE Project (278976) and was supported by the Spanish Ministerio Educación y Ciencia (MPY1072/05).

\section{References}

Arce, A., Estirado, A., Ordobas, M., Sevilla, S., García, N., Moratilla, L., de la Fuente, S., Martínez, A.M., Pérez, A.M., Aránguez, E., Iriso, A., Sevillano, O., Bernal, J., Vilas, F., 2013. Re-emergence of leishmaniasis in Spain: community outbreak in Madrid, Spain, 2009 to 2012. Euro Surveill. 18 (30), pii: 20546.

Ashford, R.W., 1996. Leishmaniasis reservoirs and their significance in control. Clin. Dermatol. 14, 523-532.

Ashford, R.W., 2003. When is a reservoir not a reservoir? Emerg. Infect. Dis. 9, 1495-1496.

Ayllón, T., Tesouro, M.A., Amusategui, I., Villaescusa, A., Rodriguez-Franco, F., Sainz, A., 2008. Serologic and molecular evaluation of Leishmania infantum in cats from Central Spain. Ann. N.Y. Acad. Sci. 1149, 361-364.

Ayllón, T., Diniz, P.P., Breitschwerdt, E.B., Villaescusa, A., RodríguezFranco, F., Sainz, A., 2012. Vector-borne diseases in client-owned and stray cats from Madrid, Spain. Vector Borne Zoonotic Dis. 12, $143-150$.

Baneth, G., Koutinas, A.F., Solano-Gallego, L., Bourdeau, P., Ferrer, L., 2008. Canine leishmaniosis - new concepts and insights on an expanding zoonosis: part one. Trends Parasitol. 24, 324-330.

Bañuls, A.L., Hide, M., Prugnolle, F., 2007. Leishmania and the leishmaniases: a parasite genetic update and advances in taxonomy, epidemiology and pathogenicity in humans. Adv. Parasitol. 64, 1-109.

Bates, P.A., 2007. Transmission of Leishmania metacyclic promastigotes by phlebotomine sand flies. Int. J. Parasitol. 37, 1097-1106.

Boelaert, M., Criel, B., Leeuwenburg, J., Van Damme, W., Le Ray, D., Van der Stuyft, P., 2000. Visceral leishmaniasis control, a public health perspective. Trans. R. Soc. Trop. Med. Hyg. 94, 465-471.

Criado-Fornelio, A., Gutierrez-García, L., Rodriguez-Caabeiro, F., ReusGarcía, E., Roldán-Soriano, M.A., Díaz-Sánchez, M.A., 2000. A parasitological survey of wild red foxes (Vulpes vulpes) from the province of Guadalajara, Spain. Vet. Parasitol. 92, 245-251.

Chelbi, I., Kaabi, B., Derbali, M., Ben Hadj Ahmed, S., Dellagi, K., Zhioua, E., 2008. Zooprophylaxis: impact of breeding rabbits around houses on reducing the indoor abundance of Phlebotomus papatasi. Vector Borne Zoonotic Dis. 8, 741-747.

Chitimia, L., Muñoz-García, C.I., Sánchez-Velasco, D., Lizana, V., del Río, L., Murcia, L., Fisa, R., Riera, C., Giménez-Font, P., Jiménez-Montalbán, P., Martínez-Ramírez, A., Meseguer-Messeguer, J.M., García-Bacete, I., Sánchez-Isarria, M.A., Sanchis-Monsonís, G., García-Martinez, J.D., Vicente, V., Segovia, M., Berriatua, E., 2011. Cryptic leishmaniosis by Leishmania infantum, a feature of canines only? A study of natural infection in wild rabbits, humans and dogs in southeastern Spain. Vet. Parasitol. 181, 12-16.

Gramiccia, M., 2011. Recent advances in leishmaniosis in pet animals: epidemiology, diagnostics and anti-vectorial prophylaxis. Vet. Parasitol. 181, 23-30.

Jiménez, M., González, E., Iriso, A., Marco, E., Alegret, A., Fúster, F., Molina, R., 2013. Detection of Leishmania infantum and identification of blood meals in Phlebotomus perniciosus from a focus of human leishmaniasis in Madrid, Spain. Parasitol. Res. 112, 2453-2459.
Karp, Ch.L., Turco, S.J., Dacks, D.L., 1991. Lipophosphoglycan masks recognition of the Leishmania donovani promastigote surface by human kala-azar serum. J. Immunol. 147, 680-684.

Lei, S.M., Romine, N.M., Beetham, J.K., 2010. Population changes in Leishmania chagasi promastigote developmental stages due to serial passage. J. Parasitol. 96, 1134-1138.

Maia, C., Gomes, J., Cristóvao, J., Nunes, M., Martins, A., Rebelo, E., Campino, L., 2010. Feline Leishmania infection in a canine leishmaniasis endemic región, Portugal. Vet. Parasitol. 174, 336-340.

Martín-Sánchez, J., Acedo, C., Muñoz-Pérez, M., Pesson, B., Marchal, O., Morillas-Márquez, F., 2007. Infection by Leishmania infantum in cats: Epidemiological study in Spain. Vet. Parasitol. 145, 267-273.

Millán, J., Zanet, S., Gomis, M., Trisciuoglio, A., Negre, N., Ferroglio, E., 2011. An investigation into alternative reservoirs of canine Leishmaniasis on the endemic Island of Mallorca (Spain). Transbound. Emerg. Dis. 58, 352-357.

Molina, R., Jiménez, M.I., Cruz, I., Iriso, A., Martín-Martín, I., Sevillano, O., Melero, S., Bernal, J., 2012. The hare (Lepus granatensis) as potential sylvatic reservoir of Leishmania infantum in Spain. Vet. Parasitol. 190, 268-271.

Moreira, D., Santarém, N., Loureiro, I., Tavares, J., Silva, A.M., Amorin, A.M., Ouaissi, A., Cordeiro-da-Silva, A., Silvestre, R., 2012. Impact of continuous axenic cultivation in Leishmania infantum virulence. PLoS Neg. Trop. Dis. 6, e1469.

Moreno, I., Molina, R., Toraño, A., Laurin, E., García, E., Domínguez, M., 2007. Comparative real-time kinetic analysis of human complement killing of Leishmania infantum promastigotes derived from axenic culture or from Phlebotomus perniciosus. Microbes Infect. 9, $1574-1580$

Moreno, I., 2010. Analysis of Leishmania opsonophagocytosis mechanism in blood of Oryctolagus cuniculus. Ph.D. Thesis. Universidad Complutense de Madrid, Department of Veterinary Pathology, Madrid, Spain.

Morillas Márquez, F., Benavides Delgado, I., Gonzalez Castro, J., Reyes Magaña, A., Valero Lopez, A., 1985. Occurrence of Leishmania sp. in Rattus rattus in the province of Granada. Ann. Parasitol. Hum. Comp. 60, 768-770.

2008. OIE Manual of Diagnostic Tests and Vaccines for Terrestrial Animals (Mammal, Birds and Bees) (Chapter 2.1.8)

(SNEDO) Sistema de Notificación de Enfermedades de Declaración Obligatoria, 2012. Diseases Transmitted by Vectors: Leishmaniasis and Paludism. Institute of Public Health, Community of Madrid.

Schmunis, G.A., Herman, R., 1970. Characteristics of so-called natural antibodies in various normal sera against culture forms of Leishmania. J. Parasitol. 56, 889-896.

Sobrino, R., Ferroglio, E., Oleaga, A., Romano, A., Millán, J., Revilla, M. Arnal, M.C., Trisciuoglio, A., Gortázar, C., 2008. Characterization of widespread canine leishmaniasis among wild carnivores from Spain. Vet. Parasitol. 155, 198-203.

Solano-Gallego, L., Fernández-Bellón, H., Serra, P., Gállego, M., Ferrer, L., 2003. Cutaneous leishmaniosis in three horses in Spain. Equine Vet. J. 35, 320-323.

Ulrich, M., Trujillo Ortiz, D., Convit, J., 1968. The effect of fresh serum on the leptomonads of Leishmania. I. Preliminary report. Trans. R. Soc. Trop. Med. Hyg. 62, 825-830.

Wheeler, R.J., Gluenz, E., Gull, K., 2011. The cell cycle of Leishmania: morphogenetic events and their implications for parasite biology. Mol. Microbiol. 79, 647-662. 